\title{
Procalcitonina como biomarcador diagnóstico de sepsis en el niño con cáncer, neutropenia y fiebre: revisión de la literatura
}

\author{
Procalcitonin as a diagnostic biomarker of sepsis in children \\ with cancer, fever and neutropenia: literature review
}

\author{
M. en C. Jesús Reyna-Figueroa, , M. en C. Alfredo Lagunas-Martínez ${ }^{b}$, \\ Dra. Pilar Martínez Matsumoto ${ }^{c}$ y Dr. Vicente Madrid-Marina ${ }^{b}$
}

\section{RESUMEN}

En los enfermos de cáncer, al igual que en los sujetos sépticos, existe desregulación de eventos comunes, comola inflamación, lo que limita el uso de biomarcadores para diagnosticarles sepsis. Mediante una búsqueda en la base de datos PubMed, identificamos los estudios clínicos que evaluaron la procalcitonina como biomarcador en niños con cáncer y sepsis, y analizamos sus características, ventajas y desventajas. La mayoría de los estudios sugieren que, con un punto de corte de $0,5 \mathrm{ng} / \mathrm{dl}$ a $1 \mathrm{mg} / \mathrm{dl}$, la procalcitonina presenta una sensibilidad de $59-78 \%$, especificidad de $76 \%$, valor predictivo positivo de $93 \%$ y valor predictivo negativo de $45 \%$ para el diagnóstico de sepsis. Los valores de procalcitonina no se modifican con el uso de la quimioterapia o el uso de esteroides y, en los últimos años, se han obtenido resultados alentadores en su uso como biomarcador en el niño con cáncer y, particularmente, con neutropenia y fiebre.

a. Programa de

Doctorado en

Ciencias de la Salud, concentración en Enfermedades Infecciosas.

b. Centro de Investigación sobre Enfermedades Infecciosas. Instituto Nacional de Salud Pública.

c. Servicio de Pediatría del Hospital Central Sur de Alta Especialidad Petróleos Mexicanos. México.

Correspondencia: M. en C. Jesús Reyna-Figueroa: jesusreynaf@gmail.com

Conflicto de intereses:

Ninguno que declarar.
Palabrasclave: neoplasias, neutropenia febril, sepsis, niño, marcadores biológicos.

\section{ABSTRACT}

Among cancer and septic patients, there is a deregulation of common events such as inflammation. This fact limits the use of biomarkers to diagnose sepsis.

Through a search in the PubMed database, we identified the clinical studies that evaluated procalcitonin as abiomarker among children with cancer and sepsis; we analyzed its characteristics, advantages and disadvantages. Most of the studies suggest that with a cut-off point between $0.5 \mathrm{ng} / \mathrm{dl}$ and $1 \mathrm{mg} / \mathrm{dl}$, procalcitonin displays a sensitivity of $59-78 \%$, a specificity of $76 \%$, a predictive value of $93 \%$ and a negative predictive value of $45 \%$ to diagnose sepsis. The procalcitonin values were not modified by the use of chemotherapy or steroids. In the past few years, encouraging results have been obtained when using it as a biomarker in children with cancer, particularly with neutropenia and fever. Key words: neoplasms, febrile neutropenia, sepsis, child, biological markers.

http:/ /dx.doi.org/10.5546/aap.2015.46

\section{INTRODUCCIÓN}

La sepsis nosocomial es una de las principales causas de muerte en el niño con neutropenia y fiebre (NF), una población en la que se producen infecciones graves, incluso tras el inóculo de una baja cantidad de bacterias $u$ hongos que no pueden detectarse solo con los cultivos, y en quienes la demora en el inicio de los antimicrobianos puede ser mortal, especialmente en la sepsis producida por las bacterias Gram negativas. Por este motivo, la fiebre en el niño con neutropenia se trata primariamente como si fuera producida por una infección. ${ }^{1}$ La sospecha de sepsis en el niño con cáncer hospitalizado tiene como consecuencia el incremento en el costo de la atención médica por el uso de los antibióticos y de los recursos diagnósticos, así como por la estancia hospitalaria prolongada. ${ }^{2}$

En los últimos años, algunos parámetros de origen biológico, denominados biomarcadores, se han asociado con la respuesta del huésped ante la invasión de algún microorganismo y han sido estudiados como una opción para diagnosticar sepsis. Se consideraron para cada uno de ellos diferentes ventajas y limitaciones. ${ }^{3-5}$ Se ha estipulado que existen, al menos, 178 biomarcadores, que son utilizados como discriminadores diagnósticos y pronósticos en sujetos con sepsis, ${ }^{6}$ cuyo objetivo principal es proveer información adicional a la clínica. La proteína C reactiva (PCR), la procalcitonina y la velocidad de sedimentación globular (VSG) son los 
biomarcadores más utilizados para fortalecer el diagnóstico y establecer el pronóstico de la sepsis. Tanto la PCR como la VSG son baratas y suelen estar disponibles en hospitales, aunque son poco sensibles y no específicas para sepsis. La PCR se eleva en todos los estados inflamatorios; sus niveles, además, no correlacionan con los estados de gravedad; se modifica con el uso de esteroides y en la falla hepática. Mientras que la VSG se modifica, además, en la deshidratación o anemia y no correlaciona con los estados de gravedad y, en muchos sitios, se considera en desuso. ${ }^{7,8}$

Debido a que la procalcitonina, en los últimos años, ha sido considerada como el biomarcador con mayor utilidad para discriminar la sepsis de origen bacteriano, revisamos, en la literatura científica, los argumentos que permitieran establecer las ventajas y desventajas al utilizar la procalcitonina para el diagnóstico de sepsis en el niño con cáncer y NF.

\section{OBTENCIÓN DE LA INFORMACIÓN}

Buscamos, en la base de datos Medline los estudios publicados en extenso de enero de 2004 a julio de 2013 en los idiomas inglés y español, utilizando las palabras clave en inglés "procalcitonin, biomarker, diagnostic, cancer and children". Además, se buscaron, en las referencias de estos artículos, los estudios con potencial para ser considerados en el texto.

Consideramos los estudios clínicos que evaluaron directa o indirectamente la utilidad de la procalcitonina para el diagnóstico de sepsis en los niños con cáncer. Las principales medidas de salida que se buscaron en cada artículo fueron la sensibilidad y la especificidad, los valores predictivos y/o las razones de verosimilitud, así como las ventajas y limitaciones reportadas por los investigadores. Para obtener la información, los autores revisaron, de manera independiente, los artículos identificados y, posteriormente, seleccionaron e incluyeron los artículos que consideraron que trataban sobre el tema, sin evaluar la calidad metodológica de los manuscritos.

\section{LA PROCALCITONINA EN LA SEPSIS}

La procalcitonina es la prohormona de la calcitonina, una proteína que induce vasodilatación principalmente en las arterias coronarias, en las arterias cerebrales y en la vasculatura sistémica en general, que, además, participa en la regulación del metabolismo del calcio. La procalcitonina es producida principalmente por las células $C$ tiroideas y, en menor cantidad, por las células neuroendócrinas pulmonares y del intestino delgado del sujeto no séptico. ${ }^{10}$ Una vez que se produce la estimulación de estas células, se inicia la transcripción del gen de procalcitonina (calcitonin-1 gene o CALC-1), con la traducción posterior de los 116 aminoácidos que componen la procalcitonina, la cual es cortada a nivel de los aminoácidos 60 a 91 y se produce la calcitonina, cuya actividad biológica más importante es disminuir la concentración sérica de calcio por inhibición de la reabsorción ósea. ${ }^{11}$

La procalcitonina también es producida en la inflamación que resulta en respuesta a las endotoxinas o a los mediadores inducidos principalmente por las infecciones bacterianas (por ejemplo, IL-1b, TNF- $\alpha$ e IL6). La sobrerregulación de la procalcitonina es atenuada por el interferón gama (INF- $\gamma$ ), una citocina liberada en respuesta a las infecciones virales, motivo por el cual la procalcitonina se considera específica para las infecciones bacterianas y poco útil en las infecciones virales. ${ }^{9}$ El comportamiento en sangre de la procalcitonina como respuesta a una infección bacteriana se encuentra esquematizado en la Figura 1, en la que se encuentra que los picos máximos se presentan a las 12 horas posteriores al inóculo bacteriano, con una vida media de 36 horas si el estímulo desaparece.

Cuando existe un proceso inflamatorio, la procalcitonina se eleva hasta 5000 veces en las primeras 2-4 horas posteriores a la infección y con una vida media de 22 a 26 horas, y persiste hasta la recuperación, aproximadamente 36 horas si el estímulo desaparece. Como diferencia, la procalcitonina en la sepsis no tiene actividad hormonal y su tamaño es de 114 aa. Además, la mayoría de la producción de la procalcitonina en un proceso infeccioso ocurre fuera de la glándula tiroidea, motivo por el cual, en pacientes con tiroidectomía que padecen infecciones sistémicas, existen niveles elevados de la procalcitonina en el suero. Las infecciones virales, el uso de esteroides y las condiciones inflamatorias crónicas no deben ser evaluados con la procalcitonina. Para ello, es preferible utilizar el conteo leucocitario sanguíneo, la PCR o la VSG. ${ }^{12}$ Contrariamente, existen estudios que sugieren que la procalcitonina no se afecta por la neutropenia, el uso de los esteroides ni de los antiinflamatorios no esteroideos, lo cual le conferiría ventaja ante la PCR, ya que esta depende de una adecuada síntesis proteica a nivel 
hepático. ${ }^{13}$ En una evaluación realizada en 163 pacientes con infección bacteriana corroborada, se encontró que los niveles de la procalcitonina son mayores en aislamientos de bacterias Gram positivas. ${ }^{14} \mathrm{Al}$ ser un biomarcador específico para las infecciones bacterianas, la procalcitonina se ha propuesto como un marcador para diferenciar las infecciones ocasionadas por las bacterias Gram positivas de las Gram negativas.

\section{LA PROCALCITONINA EN LOS PROCESOS NO INFECCIOSOS}

Aunque la procalcitonina es considerada un marcador específico de infecciones bacterianas, se ha observado hiperprocalcitonemia en algunos procesos neoplásicos de los adultos, como los tumores neuroendócrinos, el cáncer de la tiroides, el cáncer pulmonar de células pequeñas y el síndrome carcinoide. Por este motivo, la procalcitonina no es considerada un adecuado biomarcador para identificar sepsis en los sujetos que padecen alguna de estas enfermedades. ${ }^{8}$ Además, la elevación de la procalcitonina ha sido reportada en los procesos inflamatorios relacionados con trauma, cirugía, infarto de miocardio, falla cardíaca y en la encefalopatía isquémica posterior a infarto de miocardio. ${ }^{16} \mathrm{En}$ otros padecimientos con compromiso vascular, como la preeclampsia, se ha encontrado que los niveles de la procalcitonina, la PCR y del dímero $\mathrm{D}$ son mayores a los encontrados en el grupo control sano $(p=0,001) .{ }^{17}$ Además, la procalcitonina, junto con la PCR, han sido utilizadas como marcadores que detectan de manera temprana la presencia de fístulas asociadas a la realización de una gastrectomía. ${ }^{18}$

\section{LA PROCALCITONINA EN SUJETOS SÉPTICOS CON CÁNCER}

Las conclusiones de las diferentes publicaciones que evalúan la procalcitonina sola o en combinación para el diagnóstico de sepsis en el niño con NF son variadas (véase la Tabla 1). Buscando contrastar la capacidad diagnóstica de la procalcitonina con otros biomarcadores, calculamos, con los datos encontrados, los valores predictivos positivos y negativos de acuerdo con las fórmulas: razón de verosimilitud positiva $(\mathrm{RVP})=$ sensibilidad /1-especificidad, razón de verosimilitud negativa $(\mathrm{RVN})=1$-sensibilidad $/$ especificidad. Cuando un biomarcador era referido por más de dos citas, se promediaron la sensibilidad y la especificidad. Se encontró que la procalcitonina presenta una RVP de 3 y RVN de 0,4, cifras similares a las de la PCR, pero superiores a la combinación de la PCR,

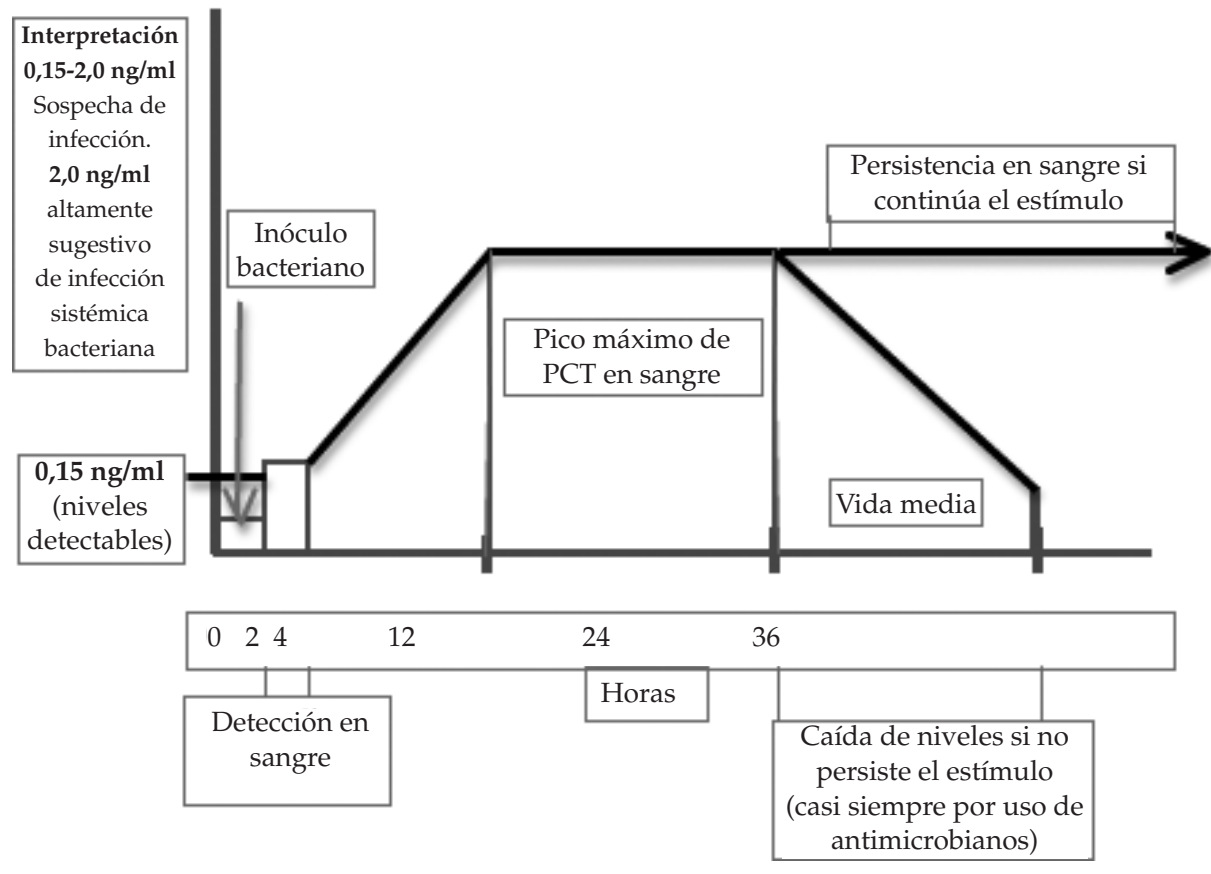


hemoglobina, leucopenia y uso de catéter en sujetos con leucemia. Sin embargo, los valores de procalcitonina fueron inferiores a los obtenidos en la combinación de la PCR, interleucina 8 y la proteína quimiotáctica de macrófagos (véase la Tabla 2).

En una publicación realizada en el año 2011, se destacan las propiedades de la procalcitonina en los pacientes sépticos en estado crítico, pero también se establece que las conclusiones de la revisión no pueden ser aplicadas a los niños, a los inmunosuprimidos ni a los sujetos con cáncer en estadio terminal, ${ }^{3}$ probablemente porque entre la sepsis y el cáncer existe desregulación de eventos, como la hipoxia, el daño tisular, la apoptosis y la inflamación, que son comunes entre ambos. ${ }^{19}$ Aun así, se han realizado algunos estudios clínicos que evalúan la capacidad como biomarcador de procalcitonina, con diversos resultados.

TABLA 2. Eficacia de procalcitonina y proteína C reactiva solas o en combinación con otros biomarcadores para discriminar bacteriemia en niños con neutropenia y fiebre por cáncer ${ }^{25-35}$

\begin{tabular}{lcc}
\hline Marcadores & Sensibilidad & Especificidad \\
\hline PCR, Hb alta, leucopenia, & & \\
catéter, LLA & 96 & 26 \\
PCR, IL-8, MCP-1 & 85 & 95 \\
PCR & 77 & 72 \\
PCT & 65 & 78 \\
\hline IL: interleucina; MCP-1: proteína quimiotáctica de monocitos; \\
PCT: procalcitonina;PCR:proteínaC Creactiva;Hb: hemoglobina; \\
LLA: leucemia linfoblástica aguda.
\end{tabular}

TABLA 1. Conclusiones de los estudios que evalúan procalcitonina y/o proteína $C$ en niños con neutropenia y fiebre para el diagnóstico de sepsis

\begin{tabular}{|c|c|c|c|}
\hline Biomarcador & Objetivo de la evaluación & Observaciones & Cita \\
\hline IL-6, PCT, PCR y LBP & Capacidad diagnóstica de LBP & $\begin{array}{l}\text { LBP es menos eficaz que IL-6, PCR y PCT } \\
\text { en predecir bacteriemia }\end{array}$ & 28 \\
\hline PCT, PCR & Discriminador de bacteriemia & $\begin{array}{l}\text { La PCT es más específica que sensible, mientras } \\
\text { que la PCR fue más sensible que específica }\end{array}$ & 23 \\
\hline PCT, PCR & $\begin{array}{l}\text { Discriminación de } \\
\text { infección documentada }\end{array}$ & $\begin{array}{l}\text { La PCT es un predictor de infección bacteriana; } \\
\text { la PCR se establece como el mejor } \\
\text { biomarcador en casos de urgencia }\end{array}$ & 24 \\
\hline $\begin{array}{l}\text { Nitrógeno ureico, } \\
\text { glucemia, DHL, PCR, } \\
\text { IL-8, PCT }\end{array}$ & Predictores de sepsis & $\begin{array}{l}\text { La PCR y la IL-8 son predictores de sepsis } \\
\text { no aparente durante las primeras } \\
24 \text { horas de hospitalización }\end{array}$ & 29 \\
\hline PCT & $\begin{array}{l}\text { Identificación de bacteriemia } \\
\text { al momento de la admisión }\end{array}$ & $\begin{array}{l}\text { La PCT es útil como indicador temprano } \\
\text { de bacteriemia; es más sensible que la PCR }\end{array}$ & 22 \\
\hline IL-6, IL-8, PCT & Determinación de sepsis bacteriana & $\begin{array}{l}\text { La PCT combinada con la IL-8 es altamente } \\
\text { sensible y específica como marcador diagnóstico. } \\
\text { La IL-6 no presentó incremento }\end{array}$ & 30 \\
\hline $\begin{array}{l}\text { IL-6, IL-8, } \\
\text { IL-10, PCR }\end{array}$ & $\begin{array}{l}\text { Comparar los niveles en niños } \\
\text { con y sin bacteriemia }\end{array}$ & $\begin{array}{l}\text { La IL-8 puede diferenciar bacteriemia en las } \\
\text { primeras } 24 \text { horas; la IL-10 diferencia } \\
\text { infección por Gram negativos }\end{array}$ & 31 \\
\hline PCT & $\begin{array}{l}\text { Evaluar la eficacia de PCT } \\
\text { en el diagnóstico de fungemia }\end{array}$ & $\begin{array}{l}\text { Poco aporta para el diagnóstico de } \\
\text { infección invasiva por hongos }\end{array}$ & 25 \\
\hline PCT, PCR & $\begin{array}{l}\text { Discriminar entre la fiebre producida } \\
\text { por el anticuerpo y la infección bacteriana }\end{array}$ & $\begin{array}{l}\text { Los niveles de PCR y PCT fueron similares } \\
\text { al administrar el anticuerpo que } \\
\text { en la infección por Gram negativos }\end{array}$ & 26 \\
\hline $\begin{array}{l}\text { IL-6, IL-8, PCR, } \\
\text { receptor soluble tipo III, } \\
\text { proteína de unión a manosa }\end{array}$ & $\begin{array}{l}\text { Indicador temprano de infección por } \\
\text { Gram negativos y hongos }\end{array}$ & $\begin{array}{l}\text { La IL-6 y la IL-8 son buenos indicadores } \\
\text { tempranos de infección }\end{array}$ & 32 \\
\hline $\begin{array}{l}\text { TNF alfa, IL-1, IL-6, } \\
\text { PCR, amiloide A sérico }\end{array}$ & Diferenciar bacteriemia & $\begin{array}{l}\text { Correlacionan con infección, } \\
\text { pero no identifican la etiología bacteriana }\end{array}$ & 33 \\
\hline IL-6, PCR & Discriminar bacteriemia & $\begin{array}{l}\text { La IL-6 es más sensible que } \\
\text { la PCR en infección aguda }\end{array}$ & 34 \\
\hline
\end{tabular}

IL: Interleucina; TNF: factor de necrosis tumoral; PCT: procalcitonina; PCR: proteína C reactiva; MCP: proteína quimiotáctica de monolitos. 
Duff et al. en 2013, estudiaron a 34 pacientes con cáncer y sospecha de sepsis. Consideraron como punto de corte diagnóstico una cifra de la procalcitonina $\geq 0,5 \mathrm{ng} / \mathrm{dl}$ y concluyeron que no existía diferencia significativa entre los sujetos fallecidos en el día 3 de la infección (media de 28 $\mathrm{ng} / \mathrm{dl}$ ) y los sobrevivientes (media de $24 \mathrm{ng} / \mathrm{dl}$ ), con una $p=0,296$. Sin embargo, cuando se analizaron los niveles de la procalcitonina estratificando por la gravedad de la sepsis, se encontró que, en los sujetos con sepsis, los niveles fueron de 5,4 $\mathrm{ng} / \mathrm{dl}$; en la sepsis grave, de 18,9 ng/dl; $\mathrm{y}$, en el choque séptico, de $36,8 \mathrm{ng} / \mathrm{dl}^{20}$

Reitman et al. analizaron los niveles de la procalcitonina al momento del ingreso hospitalario y entre las 12 y las 24 horas del inicio de la fiebre en 223 episodios febriles de niños con neutropenia. Encontraron que el estudio seriado de la procalcitonina con un punto de corte $\geq$ $0,5 \mathrm{ng} / \mathrm{dl}$ presenta una sensibilidad de $78 \%$, especificidad de $76 \%$, valor predictivo positivo (VPP) de 93\% y valor predictivo negativo (VPN) de $45 \%$ para el diagnóstico de sepsis. ${ }^{21}$ Chawes et al. compararon la utilidad de la procalcitonina y de la PCR en 55 episodios febriles de niños con cáncer en tratamiento con quimioterapia. A diferencia de los otros estudios, el punto de corte de la procalcitonina utilizado como predictor de bacteremia fue de $1 \mathrm{mg} / \mathrm{dl}$ y de $50 \mathrm{mg} / \mathrm{dl}$ para la PCR. Los autores concluyeron que la procalcitonina era más sensible que la PCR para detectar bacteremia en el sujeto con cáncer. ${ }^{22}$ Estos resultados son contradictorios a los obtenidos en un metaanalisis, en el que se incluyeron 10 estudios que evaluaron la procalcitonina y 8 que evaluaron la PCR. En este trabajo, se encontró una sensibilidad de la procalcitonina menor a la de la PCR $(0,59$; IC $95 \%$ : $0,42-0,74$ vs. 0,75 ; IC 95\%: 0,61-0,85), pero con una mejor especificidad (0,76; IC 95\%: 0,64-0,85 vs. 0,62; IC 95\%: 0,49$0,73) .{ }^{23}$ Martínez et al. también compararon ambos biomarcadores en 54 niños con NF divididos en dos grupos (bajo riesgo y alto riesgo de acuerdo con las cifras de neutrófilos encontrados). La PCR presentó una mediana de la concentración en suero en los niños con bajo riesgo de 6,78 $\mathrm{mg} / \mathrm{dl}$ (rango de 0-31) vs. 16,28 mg/dl (rango de $0,3-53$ ) en los niños con alto riesgo. Mientras que la procalcitonina presentó niveles séricos de $1,39 \mathrm{ng} / \mathrm{ml}$ (rango de 0,1-10) en los sujetos con bajo riesgo vs. $3,2 \mathrm{ng} / \mathrm{ml}$ (rango de $0,1-16$ ) en niños con alto riesgo $(p=0,003)$. Con el punto de corte de 9,06 mg/dl para PCR, se obtuvo una sensibilidad de $77,7 \%$, especificidad de $72,2 \%$, VPP de $51 \%$ y VPN de $96,2 \%$ para PCR. Mientras que, para la procalcitonina, con un punto de corte de $0,67 \mathrm{ng} / \mathrm{mL}$, se encontró una sensibilidad de $72,2 \%$, especificidad de $80,5 \%$, VPP de $68,7 \%$ y VPN de $89,4 \%$. En este trabajo, los autores concluyeron que la procalcitonina era un biomarcador más eficaz para predecir bacteremia en niños gravemente enfermos que la PCR. Además, consideraron que la PCR podía ser una mejor prueba en casos de emergencia debido a su mayor sensibilidad y disponibilidad. ${ }^{24}$ Ambos biomarcadores presentan algunas ventajas y limitantes: la procalcitonina presenta la ventaja de no modificarse con el uso de la quimioterapia en pacientes con cáncer, mientras que la PCR sí es modificable. Los dos marcadores, sin embargo, pueden elevarse en pacientes que reciben tratamiento inmunomodulador dirigido a células $\mathrm{T}$, con soporte de granulocitos o con enfermedad injerto contra huésped. Además, la procalcitonina presenta baja sensibilidad y especificidad para diagnosticar enfermedad micótica invasiva (particularmente, aspergillosis). ${ }^{25,26}$ Shomali et al. en 2012, establecieron, mediante un estudio comparativo, el papel que juega la procalcitonina como marcador que puede diferenciar la fiebre consecuencia de un proceso infeccioso de la ocasionada por la actividad tumoral en los pacientes no neutropénicos, tomando como punto de corte 0,075 ng/mL. En este trabajo, se encontró que la concentración en suero de la procalcitonina en sujetos con una infección sistémica bacteriana $(1,06 \mathrm{ng} / \mathrm{mL}$; IC 95\%, 0,075-81,95) era mayor que en los sujetos en quienes se documentó fiebre por actividad tumoral $(0,67 \mathrm{ng} / \mathrm{mL}$; IC $95 \%, 0,11$ $4,14 ; p=0,033) .{ }^{27}$ Otra estrategia que puede ser utilizada para evaluar la procalcitonina como marcador diagnóstico de sepsis en el niño con cáncer, NF, es la de cuantificar los niveles séricos de la procalcitonina en cuatro momentos que permiten establecer un patrón diferencial en su comportamiento: Grupo A) niños con diagnóstico reciente de cáncer previo al uso de quimioterapia; Grupo C) niños con neutropenia y fiebre; y Grupo D) al momento del egreso hospitalario. Esto indica que los niveles de procalcitonina son mayores en el sujeto con proceso infeccioso activo que en los individuos con actividad tumoral, y estos, a su vez, que los sujetos que se egresan del hospital. Queda pendiente la evaluación de las cifras de procalcitonina del sujeto que está recibiendo quimioterapia (Grupo B) (Figura 2). 


\section{CONCLUSIONES}

La procalcitonina tiene la ventaja de proveer información adicional al examen clínico y puede influir en la decisión de discriminar sepsis en el niño con enfermedad oncológica del que presenta fiebre por alguna causa no infecciosa. Así mismo, es reconocido su papel en el seguimiento del proceso infeccioso y en la decisión de suspender o continuar el tratamiento antimicrobiano. La procalcitonina no modifica sus valores séricos con el uso de esteroides y, en los últimos años, se han obtenido resultados alentadores en su uso como biomarcador en el niño con cáncer y, particularmente, con NF.

Sus principales desventajas pueden encontrarse más en procesos de tipo inflamatorio no infeccioso del adulto que del niño, de acuerdo con lo encontrado en la literatura. $Y$, aunque es un biomarcador de uso recurrente en los últimos años para diagnosticar sepsis, la experiencia en el niño con cáncer aún debe incrementarse y aclarar algunos puntos. Como, por ejemplo, el comportamiento de la procalcitonina en los diferentes tipos de cáncer infantil y el costobeneficio de utilizarla como un biomarcador diagnóstico de sepsis o durante la decisión de suspender o no un antimicrobiano en el sujeto con cáncer, NF y, en particular, en el que está gravemente enfermo, en el que se suele continuar el tratamiento antimicrobiano.

Probablemente, el uso de la procalcitonina en el niño con cáncer y, particularmente, en el que presenta NF como biomarcador no disminuirá el número de tratamientos antimicrobianos que se inician por sospecha de sepsis, pero puede apoyar en la toma de decisiones con una mejor evidencia que la del criterio clínico. Mientras el uso de biomarcadores que han demostrado ser útiles en el niño con cáncer para diagnosticar sepsis siga siendo opcional en algunos sitios por desconocimiento o poca disponibilidad, es poco probable que se pueda definir si su uso puede estandarizar la atención del paciente con cáncer con sospecha de sepsis.

\section{Agradecimientos}

Un agradecimiento para el Consejo Nacional de Ciencia y Tecnología (Conacyt) México por el apoyo con la beca otorgada al M. en C. Jesús Reyna-Figueroa para sus estudios doctorales en el Instituto Nacional de Salud Pública.

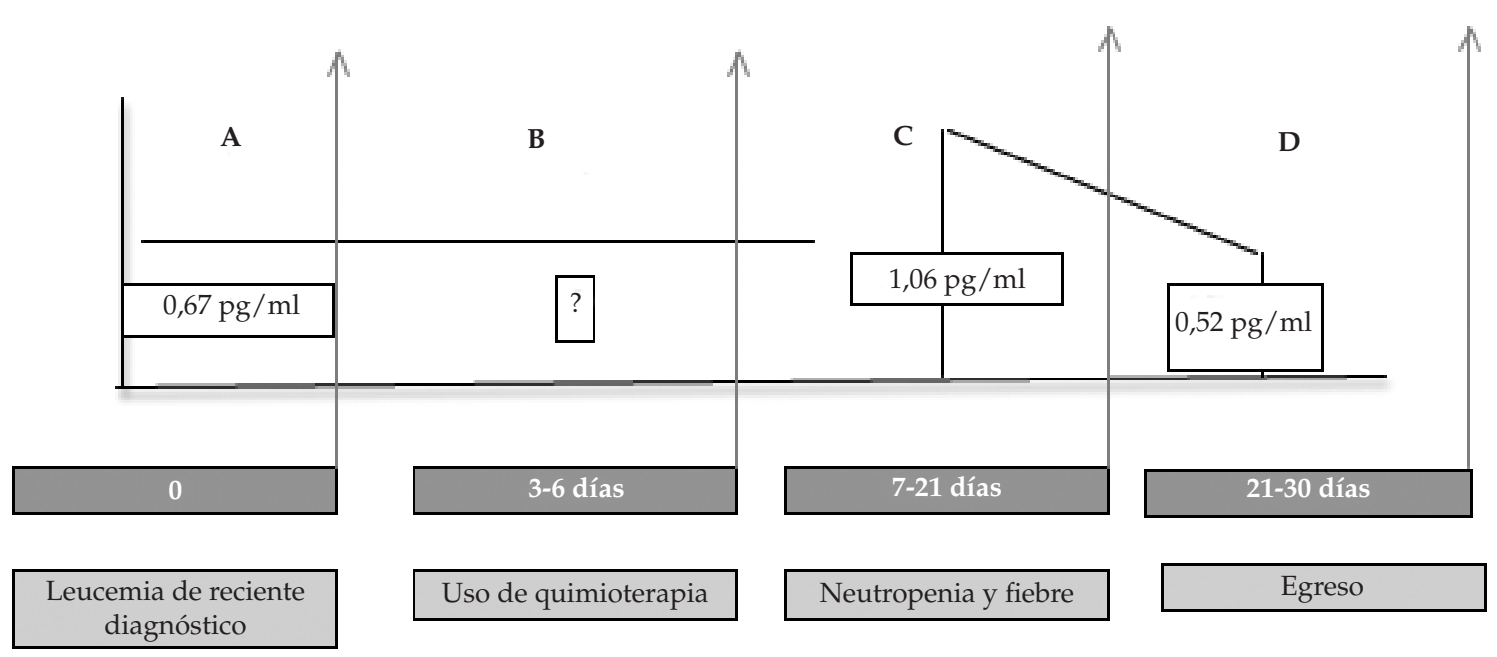




\section{REFERENCIAS}

1. Freifeld AG, Bow EJ, Sepkowitz KA, Boeckh MJ, et al. Clinical practice guideline for the use of antimicrobial agents in neutropenic patients with cancer: 2010 update by the Infectious Diseases Society of America. Clin Infect Dis 2011;52(4):e56-93.

2. Hall MJ, Williams SN, DeFrances CJ, Golosinskiy A. Inpatient care for septicemia or sepsis: a challenge for patients and hospitals. NCHS Data Brief 2011;(62):1-8.

3. Kibe S, Adams K, Barlow G. Diagnostic and prognostic biomarkers of sepsis in critical care. J Antimicrob Chemother 2011;66(suppl 2):ii33-40.

4. Smith K, Bigham MT. Biomarkers in Pediatric Sepsis. Open Inflamm J 2011;4(Suppl 1):24-30.

5. Gude D. Biomarkers in sepsis: a comprehensive review. International Journal of Clinical Cases and Investigations 2011;3(2):66-80.

6. Pierrakos $\mathrm{Ch}$, Vincent JL. Sepsis biomarkers: a review. Crit Care 2010;14(1):R15.

7. Urbonas V, Eidukaitè A, Tamulienè I. The predictive value of soluble biomarkers (CD14 subtype, interleukin-2 receptor, human leucocyte antigen-G) and procalcitonin in the detection of bacteremia and sepsis in pediatric oncology patients with chemotherapy-induced febrile neutropenia. Cytokine 2013;62(1):34-7.

8. Becker KL, Snider R, Nylen ES. Procalcitonin assay in systemic inflammation, infection, and sepsis: clinical utility and limitations. Crit Care Med 2008;36(3):941-52.

9. Schuetz $\mathrm{P}$, Albrich W, Mueller B. Procalcitonin for diagnosis of infection and guide to antibiotic decisions: past, present and future. BMC Med 2011;9:107.

10. Bloos F, Reinhart K. Rapid diagnosis of sepsis. Virulence 2014;5(1):154-60.

11. Lee H. Procalcitonin as a biomarker of infectious diseases. Korean I Intern Med 2013;28(3):285-91.

12. Foushee JA, Hope NH, Grace EE. Applying biomarkers to clinical practice: a guide for utilizing procalcitonin assays. J Antimicrob Chemother 2012;67(11):2560-9.

13. MehanicS, Baljic R. The importance of serum procalcitonin in diagnosis and treatment of serious bacterial infections and sepsis. Mater Sociomed 2013;25(4):277-81.

14. Shomali W, Hachem R, Chaftari AM, Bahu R, et al. Can procalcitonin differentiate Staphylococcus aureus from coagulase-negative staphylococci in clustered gram-positive bacteremia? Diagn Microbiol Infect Dis 2013;76(2):158-61.

15. Becker KL, Snider R, Nylen ES. Procalcitonin in sepsis and systemic inflammation: a harmful biomarker and a therapeutic target. Br J Pharmacol 2010;159(2):253-64.

16. Lateef A, KhooSM, Lee KH. Procalcitonin in hypoxic brain damage. Intensive Care Med 2005;31(3):494.

17. Kucukgoz Gulec U, Tuncay Ozgunen F, Baris Guzel A, Buyukkurt S, et al. An analysis of C-reactive protein, procalcitonin, and D-dimer in pre-eclamptic patients. Am J Reprod Immunol 2012;68(4):331-7.

18. Kassir R, Blanc P, Tibalbo LM, Breton C, et al. C-reactive protein and procalcitonin for the early detection of postoperative complications after sleeve gastrectomy: preliminary study in 97 patients. Surg Endosc 2014 Aug 27. [Epub ahead of print].

19. Konstadoulakis MM, Messaris EG. Are cancer patients adequate candidates for studying apoptosis in septic and ARDS models? Am J Respir Crit Care Med 2001;163(6):1500.

20. Duff M, Pastores S, Kostelecky N, Zhang H, et al. Procalcitonin correlates with severity of sepsis and mortality in cancer patients. Crit Care Med 2013;41(12). Disponible en: http://journals.lww.com/ccmjournal/ Fulltext/2013/12001/1032__Procalcitonin_correlates_ with_severity_of.987.aspx. [Consulta: 4 de septiembre de 2014].

21. Reitman AJ, Pisk RM, Gates JV $3^{\text {rd }}$, Ozeran JD. Serial procalcitonin levels to detect bacteremia in febrile neutropenia. Clin Pediatr (Phila) 2012;51(12):1175-83.

22. Chawes BL, Rechnitzer C, Schmiegelow K, Tvede M. Procalcitonin for early diagnosis of bacteraemia in children with cancer. Ugeskr Laeger 2007;169(2):138-42. Danish.

23. Lin SG, Hou TY, Huang DH, He SY, et al. Role of procalcitonin in the diagnosis of severeinfection in pediatric patients with fever and Neutropenia - a systemic review and meta-analysis. Pediatr Infect Dis J 2012;31(10):e182-8.

24. Martinez-Albarran M,Perez-Molina JJ, Gallegos-Castorena S, Sanchez-Zubieta F, et al. Procalcitonin and C-reactive protein serum levels as markers of infection in a pediatric population with febrile neutropenia and cancer. Pediatr Hematol Oncol 2009;26(6):414-25.

25. Dornbusch HJ, Strenger V, Sovinz P, Lackner H, et al. Non-infectious causes of elevated procalcitonin and C-reactive protein serum levels in pediatric patients with hematologic and oncologic disorders. Support Care Cancer 2008;16(9):1035-40.

26. Dornbusch HJ, Strenger V, Kerbl R, Lackner H, et al. Procalcitonin - a marker of invasive fungal infection? Support Care Cancer 2005;13(5):343-6.

27. Shomali W, Hachem R, Chaftari AM, Jiang Y, et al. Can procalcitonin distinguish infectious fever from tumorrelated fever in non-neutropenic cancer patients? Cancer 2012;118(23):5823-9.

28. Kitanovski L, Jazbec J,HojkerS, Gubina M, etal. Diagnostic accuracy of procalcitonin and interleukin-6 values for predicting bacteremia and clinical sepsis in febrile neutropenic children with cancer. Eur JClin Microbiol Infect Dis 2006;25(6):413-5.

29. Santolaya ME, Farfán MJ, De La Maza V, Cociña M, et al. Diagnosis of bacteremia in febrile neutropenic episodes in children with cancer: microbiologic and molecular approach. Pediatr Infect Dis J 2011;30(11):957-61.

30. Stryjewski GR, Nylen ES, Bell MJ, Snider RH, et al. Interleukin-6, interleukin-8, and a rapid and sensitive assay for calcitonin precursors for the determination of bacterial sepsis in febrile neutropenic children. Pediatr Crit Care Med 2005;6(2):129-35.

31. Spasova MI, Terzieva DD, Tzvetkova TZ, Stoyanova AA, et al. Interleukin-6, interleukin-8, interleukin-10, and C-reactive protein in febrile neutropenia in children with malignant diseases. Folia Med (Plovdiv) 2005;47(3-4):46-52.

32. Lehrnbecher T, Venzon D, de Haas M, Chanock SJ, et al. Assessment of measuring circulating levels of interleukin-6, interleukin-8, C-reactive protein, soluble Fc gamma receptor type III, and mannose-binding protein in febrile children with cancer and neutropenia. Clin Infect Dis 1999;29(2):414-9.

33. Riikonen $\mathrm{P}$, Saarinen UM, Perkkiö M, Hovi L, et al. Changing pattern of treatment policies invalidates the use of C-reactive protein level and hyponatremia as indicators of sepsis in children with malignancies. Pediatr Hematol Oncol 1992;9(4):365-72.

34. Ammann RA, Hirt A, Lüthy AR, Aebi C. Identification of children presenting with fever in chemotherapy-induced neutropenia at low risk for severe bacterial infection. Med Pediatr Oncol 2003;41(5):436-43. 